\title{
From Centennial to Sesquicentennial in Canada: Transformative Research in the History of Education
}

\section{Chad Gaffield}

University of Ottawa

In 1967, when Canada celebrated its centennial, little was known about the history of education, especially beyond the thoughts and ambitions of leading figures. Today, the blossoming of historical research has included significant attention to how and to what extent formal and informal education has defined personal and collective experience. In this context, Canada's sesquicentennial offered a timely opportunity to review what has been learned about Canada's educational past. Specifically, how has research enhanced our knowledge and understanding of the ways in which education has reflected and influenced social, economic, cultural, and political changes? Moreover, how can this research contribute to the making of a better future?

In order to address these questions from multiple perspectives and with attention to diverse historical contexts, members of the Making History Educational Research Unit/ Faire de l'histoire: récits et mémoires collectives en éducation at the University of Ottawa with the collaboration of the editors of Historical Studies in Education/ Revue d'histoire de l'éducation invited submissions for a special issue that would look backwards as well as forward in light of the major research findings of the past halfcentury. The call for papers asked "What do we know today about histories of education in Canada and their roles in shaping people and events that we did not know fifty years ago?"

The positive response to this invitation has resulted in five compelling illustrations of research on the causes and consequences of schooling in Canada's past. While no single collection of articles can do justice to the substantial research accomplishments of recent decades, the authors in this issue call our attention to important research findings that provide points of departure for future projects. The editors hope that their work will inspire additional efforts to synthesize research findings on other educational topics. Moreover, by presenting their articles in accessible formats designed for both specialist and non-specialist audiences, the authors make clear their 
enduring conviction - despite discouraging precedents - that enhanced historical knowledge can help improve student learning in Canada.

In "The Writing of Women into Canadian Educational History in English Canada and Francophone Quebec, 1970 to 1995," Sharon Cook, Ruby Heap, and Lorna McLean illustrate how women-centred scholarship began transforming knowledge of Canada's educational past. The authors interconnect an array of initiatives involving not only unprecedented research projects and scholarly publications but also the establishment of new associations, new publishing outlets, and new academic courses and programs. They situate the new scholarship within second-wave feminism as well as in the blossoming of social history in the 1970s. In this way, Cook, Heap, and McLean show how the emergence and development of a feminist educational history was both separate from, and at the heart of, the larger scholarly and societal changes of the post-centennial decades. Moreover, this article demonstrates the importance of connecting the analysis of publications with an understanding of larger roles played by the leading researchers both formally and informally, and on campus and in the larger society. While the authors do not use the expression, their synthesis points towards what was later called "engaged scholarship," where researchers see their work in teaching, research, and service in seamlessly connected ways, bridging between university campuses and communities. The central work of feminist educational historians in this fundamental redefinition of academic thinking and practice includes significant insights that deserve a wider readership.

This article also illustrates how significant change in a research field often depends upon developments outside of, as well as within, the field itself. In the case of educational history, change resulted from initiatives in multiple settings, some of them not located in established structures. The authors emphasize how the founding of the Canadian Research Institute for the Advancement of Women/Institut canadien de recherche sur les femmes in 1976 brought together diverse scholars as well as public activists and thereby strengthened the developing feminist critique on campus and beyond. Similarly, the authors show how women scholars and feminist research projects also played key roles in the development of the Canadian History of Education Association/Association canadienne d'histoire de l'éducation and its new journal, Historical Studies in Education/Revue d'histoire de l'éducation. Such efforts accelerated change in established disciplines by supporting women's participation in conferences, committees, and organizational initiatives, such as those led by the Canadian Committee on Women's History/Comité canadien de l'histoire des femmes within the Canadian Historical Association.

Similarly, the authors emphasize how the development of women-centred scholarship in educational history involved academic programming, beginning with upperlevel undergraduate and graduate courses in certain universities. During the 1970s, the focus of such programming was in Ontario, led by the University of Toronto and especially the Ontario Institute for Studies in Education, which offered its graduate programs in education. During the 1980s, feminist scholars in many parts of Canada began making major contributions towards a rethinking of the educational past, including those in Quebec as well as in the West. By the 1990s, every faculty of 
education, as well as departments throughout the social sciences and humanities, offered academic programming that included at least some women-centred scholarship on Canada's educational past. This article concludes by identifying the subsequent years of concerted research attention that went beyond the "racialized White, middle class, able-bodied, heterosexual women and girls" that were the focus of the transformative scholarship after the 1960s.

One of the key strengths of the article by Cook, Heap, and McLean is its attention to French-language as well as English-language work. Their article illustrates that, while most Canadian historical research operates in two linguistic solitudes, feminist scholars have, relatively speaking, been more proactive in working across borders including those between Quebec and the rest of Canada. This characteristic may further explain the central importance by the mid-1990s of the "writing of women into" Canada's educational past.

But what actually happened in classrooms as they became increasingly important after the early nineteenth century? The second article by Penney Clark and Amy von Heyking, "Back to School? Historians and the View from the Classroom," invites readers to look behind changing ambitions, policies, and structures to consider the evidence and insights offered by researchers who have focused on the experience of going to school. The authors emphasize how researchers have grappled with theoretical and methodological challenges and opportunities, especially those related to the extant historical record. Their examination of research on classrooms highlights the multiple ways in which educational historians have not only enhanced our knowledge but have also contributed to larger epistemological debates as scholars expanded their gaze to include children, culture, and experience.

The focus of scholars on classrooms followed an initial period of considerable research on school attendance. This research raised major questions about the interplay of the societal ambitions of the so-called school promoters and the changing experience of growing up across diverse groups. While the evidence reveals rapid increases in overall attendance in the age of common schooling, multiple studies showed the extent to which aggregate patterns included quite distinct sub-patterns related to individual, family, and community contexts. In light of these studies, researchers then began looking behind the school door to gain a deeper appreciation of the significance and meaning of going to school. In examining the resulting research findings, Clark and von Heyking identify how the study of classrooms offers multiple opportunities for deepening our knowledge by interrelating the built environment with policy and practice.

To some extent, research on classrooms is relatively straightforward. Clark and von Heyking emphasize how scholars began documenting the changing material characteristics of schools and classrooms. They discuss studies of educational facilities from blackboards to playgrounds as well as fragmentary evidence of how students remembered their experiences. The authors also highlight research on the move from teacher-centred to child-centred theories of schooling as well as on the introduction of IQ tests during the earlier twentieth century. While no synthetic article can completely cover the rich array of studies of changing school life, this discussion does 
suggest the many ways in which the question of school attendance is simply a point of departure for researchers seeking to come to grips with the individual and societal impact of formal education.

In examining the major research insights from studies on classrooms, Clark and von Heyking include welcome attention to the challenge of studying children whose own voices are quite absent in the archival record. Following the 1970s, educational researchers became increasingly interested in studying children's perspectives and experiences, especially in the context of a children's culture that was distinct from adult culture. As Clark and von Heyking highlight, scholars turned to written memories or to rereading adult-created sources "against the grain" (as it was often said by the 1980s) in order to infer what children may have been thinking and doing. For those studying the twentieth century, oral history became widely used, especially after initial studies raised questions about the extent to which educational theories and ambitions had real impact in the lives of children. While Clark and von Heyking focus on English-language research, they conclude with calls for greater scholarly attention to the diversity of classroom experience in Canada in order to gain a better understanding of the specific articulations of general trends in school architecture, classroom organization, and other characteristics of educational change.

In examining a half-century of educational research, Clark and von Heyking observe that classrooms have changed slowly over the years. Rather than being "transformed" at any point, they were "renovated" at various times, in keeping with new perspectives not only among educators but also, for example, among architects. Nonetheless, the authors do note that studies have shown that, in some cases, societal events can quickly change classroom activities, as was found in research on schooling during the Second World War. In this sense, this article is an important reminder that studies of Canada's educational past characteristically do not simply add to other research efforts but rather interrelate with them in expected and unexpected ways for the greater benefit of historical understanding.

The third article in this special issue demonstrates that even significant research achievements may not have much impact on important aspects of the student experience or their perspectives on the past and present. In "Combien ou comment? Les femmes canadiennes dans les récits scolaires et dans la mémoire collective, rétrospective des recherches depuis 1980," Marie-Hélène Brunet reviews multiple studies that find a continuing weak presence of women in our collective memory, including general historical narratives, school programming, and textbooks. This consistent conclusion correlates with those of surveys in which teachers and students were asked about their own historical perspectives. These findings reveal the enduring legacy of associating men far more than women with the important features of historical change. Moreover, recent curriculum additions dealing with feminist movements in the past unintentionally cultivate a sense in students that such movements are not needed today. Brunet concludes that the emergence and development of robust academic research has paralleled remarkable continuity, not only in the content of instructional material but also in the historical consciousness of teachers and students. 
By bringing together research on instructional material with studies of collective memory among teachers and students, Brunet emphasizes the complexity of cultural as well as pedagogical change. Educators cannot assume that curriculum additions will make a meaningful difference to classroom thinking. Rather, it seems that specific attention must be paid to the type of addition. For example, Brunet suggests that the current emphasis on the success of the federal suffrage campaign might be replaced by a fulsome analysis of the long struggle that finally ended in this achievement. In this way, students (and teachers) would appropriately learn about the deep and broad challenge of changing the dominant thinking about women even in the single case of electoral politics.

Brunet's discussion of research on textbooks deserves special attention, since major projects in Quebec have shown the value of systematically studying what students were reading at various times in the educational past. Most notably, the dedicated leadership of Paul Aubin and many of his colleagues has resulted in an increasingly comprehensive bibliography of school textbooks used in Quebec and elsewhere that is accompanied by a significant digital corpus for continuing research. This initiative covers three centuries quite well, and thus offers scholars the chance to examine both specific contexts and long-term content changes. By linking such research to presentday surveys and curriculum research, Brunet stimulates consideration of the extent of continuity and transformation in Canada's educational past.

The conclusion that women are still not well-represented in either instructional material or historical consciousness in education is further emphasized by $\mathrm{R}$. Fine-Meyer and K. Llewellyn in "Women Rarely Worthy of Study: A History of Curriculum Reform in Ontario Education." This article synthesizes research findings not only on the content and character of curriculum reform in one province but more importantly on its near-negligible impact over the past fifty years. The central conclusion of this synthesis complements Brunet's contribution to this special issue by highlighting the larger need for systemic and structural change in Ontario schooling. Fine-Meyer and Llewellyn show that, without such significant change, the historical record provides little reason to think that the curriculum struggle for gender equity can have significant impact. In fact, studies have shown consistently that, despite various concerted efforts over the years, schools continue to reflect the historically-entrenched privileged position of men.

Within this conclusion, Fine-Meyer and Llewellyn highlight the harmful "myths of super girls and failing boys" as well as the consequences of initiatives such as a new course on gender that "often negates the oppression of women at the hands of men with a kind of journalistic approach to 'seeing both sides." Moreover, their research review raises concern that Ontario's attempt to develop historical thinking skills may subtly re-inforce masculinist mindsets that work against effective gender analysis of change. Similarly, Fine-Meyer and Llewellyn cite research on how wellestablished historical periodization reflects men's experiences in ways that downplays or obscures women's history. Such examples suggest that the past half-century has not only witnessed little positive change but has also produced unexpected negative consequences. The article concludes by speculating that current pressures to rethink 
the curriculum in light of Indigenous knowledge may force the needed systemic and structural educational changes that, along the way, may provide the occasion for meaningful gender equity in the classroom experience.

Fine-Meyer and Llewellyn's concluding thought sets the stage for Jane Griffith's focus on research dealing with Indian residential schools. This final article of the special issue describes how such research has recently moved to the centre of scholarly and public debate after limited efforts during the first decades after Canada's centennial events. In "Off to School: Filmic False Equivalence and Indian Residential School Scholarship," Griffith reminds readers that the last residential school closed only in 1996, years after substantial research had rewritten many other aspects of the educational past. It is also worth remembering that Canada's post-secondary institutions only began offering unconditional admission to Indigenous peoples in the early 1960s. The good news is that Griffith can now bring together substantial research results, many of which became foundational for the Truth and Reconciliation Commission of Canada (TRC). The bad news is that Griffith also sees that the enduring legacy of the mindset and actions underpinning Indian residential schools is proving to be highly resilient despite withering scholarly critiques.

Of particular note in this article is Griffith's move beyond textual sources to emphasize the importance of other kinds of evidence, including visual and oral. In fact, the article opens by describing a National Film Board documentary that grouped Indian residential schools with rural schools servicing large catchment areas and school trains that visited distant communities. Produced in 1958, this documentary offers Griffith the occasion to discuss both the limited, superficial similarities between these types of schools and also their profound differences in denying the tragic consequences of settler educational colonialism for Indigenous peoples. The author's careful content analysis of the film's images and narrative illustrate one of the ways that educational historians have moved beyond history as a text-based discipline during recent decades. More recent films are discussed in the article's conclusion. Similarly, Griffith emphasizes how researchers have developed increasingly sophisticated approaches to undertaking and interpreting oral history, especially in the case of the memories of former students of Indian residential schools. These approaches call for multifaceted training in which interviewers learn "how to bear witness" in listening to a survivor's experience. While Griffith does not discuss the availability of such training, readers may justifiably wonder how many history departments have actually revised their academic programs accordingly.

Taken together, the articles in this special issue help explain why the emergence and rapid development of historical research on education did not help fuel a celebratory mood during Canada's sesquicentennial year. In fact, this research makes clear that the newly confident and optimistic spirit of fifty years ago was largely evidence-free and conceptually unexamined. Moreover, the limited educational studies done before the 1970s characteristically focused only on certain English-language and French-language experiences and were framed in terms of steady educational progress for the benefit of all Canadians. These studies were also all written by men in 
keeping with the dominant cultural practice of the time. In contrast, the research of the past half-century has been undertaken by an increasingly diverse community of scholars, especially feminist scholars, whose compelling work has been transforming our knowledge and understanding of formal schooling throughout Canada.

Perhaps the dominant conclusion reached by historical research on education in Canada is that context matters at multiple interrelated levels from local to global and from individual to collective. While four of the five articles in this special issue use a wide-angle lens to examine a half-century of educational research, each is based on research results from projects using innovative research strategies developed over the years. Microhistory first became a preferred approach in the 1970s as historians focused on the history of children, women, and families more than the ambitions of leading educators and school promoters. The linguistic turn of the 1980s inspired studies of education in terms of state projects to construct populations with specific cultural mindsets. The subsequent rise of transnational history de-emphasized jurisdictional boundaries in favour of research on the intended and unintended flows of ideas and practices across specific times and places. As illustrated by this special issue, these research strategies are now combining with other approaches to deepen our understanding of similarities and differences in educational experience. While hardly capturing the full range of recent studies, these articles appropriately emphasize the importance of inclusively drawing upon insights and evidence from all types of historical research in order to appreciate how context matters in education. Future reviews of educational historiography will undoubtedly also consider the results of diverse types of digitally enabled research, including text mining, spatial analysis, and visualizations. We can also expect increased attention to projects that link such research with historical pedagogy.

Finally, the articles make clear that educational continuity and change are deeply complex processes. While some changes seem predictable at least in hindsight, the authors also make clear that major initiatives can have limited results. In general, the educational past demonstrates that new policies might well have unintended consequences; in fact, they might strengthen rather than change existing patterns. In other words, historical research into the meaning and significance of formal schooling does not provide easy answers or reveal best practices in education. Nonetheless, the authors of the following articles imply an enduring commitment to schooling for its potential, however often unrealized, to help make a better future. Their emphasis on the importance of multiple contexts and deep complexity in the educational past encourage continued efforts to "fail better" (to borrow the compelling phrase of Samuel Beckett) by both learning from and moving beyond the school-related thinking and action of our ancestors. In a similar way, Justice Murray Sinclair explained, following the release of the report of the Truth and Reconciliation Commission of Canada, that "we think, in the long term, that while education is what got us into this situation, we think education is the key to reconciliation." ${ }^{1}$ In presenting this special issue, the editors hope that it can help Canada fail better for the benefit of all in the twentyfirst century. 
8 Historical Studies in Education/Revue d'histoire de l'éducation

\section{Notes}

1 Quoted in Kerry Benjoe, “TRC: Reconciliation through Education," Regina Leader-Post, February 25, 2016, http://leaderpost.com/news/local-news/ trc-reconciliation-through-education. 